\title{
A LINGUAGEM ESCRITA NA PERSPECTIVA \\ DE EDUCADORES: SUBSÍDIOS PARA PROPOSTAS \\ DE ASSESSORIA FONOAUDIOLÓGICA ESCOLAR
}

\author{
Written language in the teacher's perspective: \\ support for the speech therapist performance in the school
}

Jáima Pinheiro de Oliveira ${ }^{(1)}$, Rosyane Meyre Pimenta Natal (2)

\begin{abstract}
RESUMO
Objetivo: descrever uma proposta que contribua para o planejamento de ações de promoção de saúde em Fonoaudiologia Educacional, com base em uma investigação de concepções de educadores, acerca do processo de desenvolvimento da linguagem escrita. Método: estudo descritivo realizado por meio da aplicação de questionários em dezenove professores do Ensino Fundamental de três escolas da rede pública de uma cidade do interior do Estado do Paraná. Os questionários continham perguntas acerca do processo de desenvolvimento da linguagem escrita, bem como fatores que o favorecem e/ou dificultam. A análise de dados foi feita por meio da transcrição e tabulação de respostas discursivas e de múltipla escolha. A partir do conteúdo apresentado nas respostas, foram criadas categorias temáticas a serem discutidas. Resultados: foram constatados sete $(35 \%)$ relatos de que o processo de desenvolvimento da linguagem escrita inicia-se na fase escolar; O contato com materiais escritos foi citado doze $(30 \%)$ vezes como apoio para o desenvolvimento da linguagem escrita; Os aspectos individuais foram relatados dezesseis (38\%) vezes como causas das dificuldades de aprendizagem; E, houve doze (39\%) relatos de encaminhamentos a outros profissionais como solução para essas dificuldades. Conclusão: os educadores possuem carência de conhecimentos fundamentais para a sua prática pedagógica, no que concerne o processo de alfabetização, muito embora a maioria tenha formação condizente com o que é preconizado pela LDB. Não é possível generalizar tal conclusão, em função da pequena amostra do estudo.
\end{abstract}

DESCRITORES: Fonoaudiologia; Promoção da Saúde; Professor; Linguagem Infantil

\section{INTRODUÇÃO}

A promoção do desenvolvimento infantil, sem dúvida, está entre as principais preocupações de pesquisadores, seja no cenário nacional ${ }^{1-3}$ ou internacional|4-6.

Dentro desse contexto, os aspectos da promoção de saúde assumem grande dimensão e,

(1) Docente do Departamento de Fonoaudiologia da Universidade Estadual do Centro-Oeste, UNICENTRO, Irati, Paraná, Brasil; Doutora em Educação pela Universidade Estadual Paulista, UNESP, Marília, SP, Brasil; Mestre em Educação Especial pela Universidade Federal de São CarIos, UFSCar, São Carlos, SP, Brasil.

(2) Fonoaudióloga Clínica, Curitiba, Paraná, Brasil; Graduada pela Universidade Estadual do Centro-Oeste, UNICENTRO, Irati, Paraná, Brasil.

Conflito de interesses: inexistente tornaram-se um dos focos da Fonoaudiologia. Em função disso, a atuação do fonoaudiólogo deixou de ser essencialmente clínica e passou a ganhar espaço nas instituições, com um foco diferenciado, ou seja, buscando ações que beneficiassem um maior número de indivíduos. Essa atuação ganhou reconhecimento, principalmente em escolas, ambiente no qual a Resolução $n^{\circ} 309$ do ano de 2005, do Conselho Federal de Fonoaudiologia ${ }^{7}$ recomenda que:

[...] o fonoaudiólogo deve desenvolver ações em parceria com educadores, que contribuam para a promoção, aprimoramento e prevenção de alterações dos aspectos relacionados à audição, linguagem (oral e escrita), motrici- 
dade oral e voz e que favoreçam e otimizem o processo de ensino e aprendizagem.

Nessa resolução, afirma-se ainda que tal atuação pode ser feita através de capacitação e assessoria, com palestras e orientações. $O$ foco de atuação deixou de ser apenas a manifestação passando a levar em consideração questões particulares da sociedade em que se trabalha.

Observa-se, portanto, que essa mudança passa a valorizar mais aspectos voltados para a promoção da saúde. Promover a saúde implica em conhecer as necessidades da população abrangida, levando em conta fatores contextuais. Não se restringe somente a controlar fatores etiológicos, mas também a elaborar estratégias de ação voltadas ao coletivo. O objetivo não é tornar a população dependente do profissional, mas sim dar autonomia para que possa promover, por si só, a saúde. A este respeito, Sícoli e Nascimento ${ }^{8}$ dizem:

Intimamente relacionada à vigilância à saúde e a um movimento de crítica à medicalização do setor, a promoção de saúde supõe uma concepção que não restrinja a saúde à ausência de doença, mas que seja capaz de atuar sobre seus determinantes. Incidindo sobre as condições de vida da população, extrapola a prestação de serviços clínicoassistenciais, supondo ações intersetoriais que envolvam a educação, o saneamento básico, a habitação, a renda, o trabalho, a alimentação, o meio ambiente, o acesso a bens e serviços essenciais, o lazer, entre outros determinantes sociais da saúde (p.102).

Essa nova forma de atuar fez o eixo patologiatratamento-controle de doenças se deslocar para - eixo saúde/promoção da saúde e as ações fonoaudiológicas destacam-se, cada vez mais, no processo de desenvolvimento infantil. Esse destaque ocorre, principalmente, em função da necessidade de serem considerados os ambientes domiciliar e escolar na prática profissional e, por isso os aspectos da saúde comunitária constituem foco de atenção $0^{1,9}$.

Especificamente sobre a atuação fonoaudiológica em ambiente escolar, deve-se priorizar a troca de conhecimentos entre os profissionais que atuam no local e oferecer subsídios para o aproveitamento do potencial infantil, gerando condições essenciais que propiciam, por sua vez, o desenvolvimento satisfatório da criança ${ }^{10}$.

Assim, essa participação do fonoaudiólogo na equipe de planejamento escolar, prevista em lei, deve ter $\mathrm{o}$ intuito de colaborar nesse processo, pois não cabe ao fonoaudiólogo a elaboração do planejamento, entendido como tarefa essencialmente pedagógica. No entanto, uma vez que essa troca de conhecimentos gira em torno de todo esse processo pedagógico, a formação profissional do fonoaudiólogo permite uma contribuição com o intuito de aperfeiçoar todo o processo de desenvolvimento infantil ${ }^{11}$.

Alguns trabalhos, como o de Calheta ${ }^{12}$ exemplificam ações voltadas para a promoção da saúde. Essa autora desenvolveu um estudo no município de São Caetano do Sul, SP, em escolas públicas de educação infantil. Tal ação realizada por meio de assessoria aos educadores das instituições de ensino teve o letramento como tema de maior destaque reflexivo nas discussões. Este trabalho apresentou as principais diretrizes do trabalho do Fonoaudiólogo ancoradas no processo de assessoria fonoaudiológica. Para a realização de atividades focadas na promoção da saúde, foram realizados encontros com frequência semanal e 90 minutos de duração. Temas como a definição de letramento e sua contribuição ao fazer educacional, metodologias de alfabetização, técnicas pedagógicas predominantemente utilizadas pelo professor em sala de aula e possíveis inserções/transformações foram debatidos nos encontros. Em seguida, foram apresentadas algumas possibilidades em termos de atividades a serem desenvolvidas pelos educadores. Por fim, no grupo de assessoria fonoaudiológica, fonoaudiólogos e professores teceram comentários e elaboram estratégias de ação, considerando as características peculiares de cada atividade pedagógica e as possibilidades de uso da linguagem, pelas crianças.

No trabalho de Luzardo e $\mathrm{Nemr}^{13}$, as autoras desenvolveram um projeto a fim de verificar a eficácia de orientações fornecidas a 104 educadores infantis, realizadas por meio de leitura de periódicos. Foram aplicados questionários antes e depois e feita uma comparação das respostas obtidas. Essas respostas foram classificadas em quatro níveis, de acordo com a qualidade apresentada. Para as questões relacionadas ao atraso de linguagem, 4,8\% dos professores apresentaram rebaixamento nas respostas. Após a aplicação de um programa de instrumentalização, esse índice foi para $46,2 \%$. Os outros $49 \%$ não apresentaram mudanças nas respostas. Antes da implementação do programa, $11,5 \%$ disseram que encaminhariam os casos de atraso de linguagem ao fonoaudiólogo e depois do programa esse número se elevou para $20,2 \%$. As autoras concluíram que o programa de orientação foi eficaz, contribuindo com a melhora da qualidade das respostas apresentadas pelos professores. 
Por outro lado, embora nesse artigo não tenha sido possível visualizar o questionário aplicado, observa-se que ainda permanece uma preocupação em relação aos encaminhamentos dos casos para atendimento fonoaudiológico. Na verdade, a tendência dessa preocupação é diminuir, haja vista que nas propostas dentro de uma perspectiva de assessoria, as ações devem focar discussões e planejamentos que contemplem todos os aspectos fonoaudiológicos no próprio âmbito escolar ${ }^{10,11}$. Claro que há casos e, sempre haverá, que necessitam sim desse encaminhamento para avaliações especializadas.

Fernandes e Crenitte $^{14}$ investigaram qual 0 conhecimento dos professores de $1^{\text {a }}$ a $4^{\underline{a}}$ série quanto ao distúrbio de leitura e escrita. Os dados foram obtidos por meio da apresentação de um questionário a 50 professores, sendo que as respostas foram analisadas estatisticamente. Os resultados mostraram que os professores possuem um conhecimento superficial a respeito das dificuldades em leitura e escrita e permanece uma visão limitada sobre a atuação fonoaudiológica nesses casos. Os distúrbios de leitura e escrita foram interpretados pelos educadores como sendo uma falha da criança, sendo pouco reconhecida como uma falha que também pode ter outras origens como a metodologia de ensino.

A concepção que qualquer profissional tem acerca das alterações que podem ocorrer no desenvolvimento infantil refletem diretamente em sua atuação. O estudo das concepções ajuda a ampliar a compreensão por parte deste profissional e pode ser utilizado, no sentido de auxiliar em todo o processo de desenvolvimento ${ }^{9}$. Na saúde coletiva também é considerada fundamental a relação entre os conhecimentos adquiridos pelos profissionais e sua conduta no trabalho, pois estes conhecimento podem limitar ou ampliar sua prática, que requer, por sua vez, uma compreensão ampla de processos educativos ligados às questões de saúde ${ }^{15,16}$. Isso significa que, mesmo tratando-se de aspectos de saúde, o fonoaudiólogo em âmbito escolar deve assumir uma posição educacional, com propostas que vão ao encontro do trabalho pedagógico ${ }^{10,17}$.

Há também alguns trabalhos de caráter multidisciplinar, voltados para Educação Infantil, que preservam esse foco de promoção da saúde. Em estudo recente ${ }^{18}$, os autores tiveram o objetivo de descrever um trabalho de promoção da saúde desenvolvido por uma escola de educação infantil que incorpora princípios de promoção da saúde em sua prática pedagógica. $O$ estudo foi realizado numa escola particular de Educação Infantil, composta por uma equipe multidisciplinar, atendendo aproximadamente 140 crianças de 2 a 6 anos. Foram realizadas entrevistas com os profissionais da escola, as quais evidenciaram que a inserção de projetos da área de saúde está relacionada com a proposta curricular da escola. Os resultados indicaram que os temas abordados em entrevistas indicavam a necessidade de uma dupla função: um trabalho com as crianças e outro com os pais. Porém, os autores indicaram a abordagem dos pais no sentido de informá-los sobre o trabalho da escola. Verificou-se também que os temas citados foram unicamente aqueles nos quais houve uma integração maior entre os demais profissionais da escola, pais e alunos.

Por outro lado, o estudo alertou para a necessidade de se realizar um trabalho sistemático de formação com pedagogos e profissionais de saúde, para que compreendam a importância da efetivação de uma prática interligada e presente da educação em saúde nos diversos âmbitos de atuação da escola. Além disso, foi verificada a necessidade de uma revisão das propostas curriculares dos centros de formação de educadores em saúde, sejam eles profissionais de saúde ou da educação, pois tal medida objetiva a incorporação, nos diversos cursos, de um trabalho de conscientização sobre a importância do desenvolvimento compartilhado de atividades. Sem dúvida, essa forma de entendimento vai ao encontro das novas propostas de assessoria fonoaudiológica em âmbito escolar.

Com o objetivo de também avançar nessas novas propostas, Oliveira et al ${ }^{10}$ propuseram práticas fonoaudiológicas em três centros de educação infantil, voltadas para os alunos e os professores. Sobre as ações voltadas para os professores, foram destacados os mini-cursos, com encontros que priorizavam trocas de conhecimentos entre a equipe de trabalho e os educadores. As autoras alertaram para o fato de fornecer conhecimentos e condições para que esses profissionais tenham acesso a informações complementares sobre os temas tratados, pois essas informações norteiam a maior parte de suas práticas pedagógicas. A partir das discussões também foram elaboradas atividades a serem praticadas junto aos alunos. As autoras concluíram que os mini-cursos possibilitaram várias trocas de conhecimentos entre os educadores a equipe do projeto. Além disso, foi possível constatar por meio de relatos dos professores, que essa prática favoreceu, substancialmente, a formação destes profissionais, auxiliando-os em todo o planejamento pedagógico com as turmas, principalmente em relação às atividades voltadas para o desenvolvimento linguístico e o cognitivo.

Observa-se que as práticas da fonoaudiologia voltadas para a promoção de saúde ainda estão sendo construídas, principalmente em seus 
aspectos teóricos. Aos poucos, há uma tentativa de se desvincular do antigo foco preventivo, com abordagens que vão ao encontro das mudanças em diretrizes e políticas nacionais e internacionais de saúde pública, sofridas nos últimos 20 anos. Essa tendência é que norteia, cada vez mais, as propostas de inserção da fonoaudiologia na saúde coletiva, vertendo-as para um modelo de atenção, na organização dos serviços, nos papéis desempenhados pelos atores sociais e na formação dos profissionais, tanto da saúde, quanto da educação. É claro que em meio a essas mudanças, ainda permanece uma diversidade de interpretações em relação ao conceito de promoção de saúde.

O objetivo desta pesquisa foi descrever uma proposta que contribua para o planejamento de ações de promoção de saúde em Fonoaudiologia Educacional, tendo como base uma investigação de concepções de educadores, acerca do processo de desenvolvimento da linguagem escrita.

\section{MÉTODO}

\section{Caracterização do estudo}

O estudo foi classificado quanto a sua abordagem, em qualitativo, já que foi considerada a subjetividade dos sujeitos participantes, interpretada por meio de respostas e relatos fornecidos no instrumento aplicado (questionário). Quanto ao tipo, a pesquisa classificou-se como descritiva, de caráter exploratório, com a utilização da técnica de aplicação de questionário para coleta de dados ${ }^{19}$.

\section{Participantes e critérios para participação no estudo}

O trabalho foi realizado com 19 professores atuantes no primeiro segmento do Ensino Fundamental de três escolas públicas de uma cidade do interior do Paraná. Os principais critérios para seleção destes foram: disponibilidade e interesse em participar de forma voluntária no estudo e atuação em anos iniciais do Ensino Fundamental. Todos os participantes eram do sexo feminino e a idade destes variou de 26 a 50 anos.

\section{Locais}

A pesquisa foi aplicada em três escolas de Ensino Fundamental de uma cidade de pequeno porte do Estado do Paraná. Tais escolas correspondiam ao local de atuação dos professores que aceitaram participar do estudo e, todas eram de ensino público gratuito. As mesmas se localizavam em bairros centrais da cidade e, de modo geral, possuíam escolares com perfil socioeconômico diversificado, variando de classe média baixa à alta. Sobre a metodologia de alfabetização, em todas elas, os educadores afirmaram seguir a analítica, com base na teoria construtivista. A direção de cada escola autorizou a realização da pesquisa e o ambiente de coleta de dados constituiu de uma sala de atividades pedagógicas. Essa coleta, porém, só teve início após essa autorização e assinatura de um Termo de Consentimento Livre e Esclarecido (TCLE), pelos professores.

\section{Procedimentos para coleta e análise de dados}

O procedimento de coleta consistiu da aplicação de questionário junto aos professores. Os questionários foram deixados na escola por um período prédeterminado (cinco dias) e, em seguida, recolhidos para fins de análise e retorno junto a estes profissionais. O questionário continha questões sobre o processo de desenvolvimento da linguagem escrita, fatores que favorecem esse processo, a origem das dificuldades relacionadas a ele e a conduta diante dessas dificuldades. Neste questionário havia questões discursivas e de múltipla escolha (sim e não).

Para a análise das respostas obtidas, foi realizada uma transcrição das mesmas, na íntegra, e uma quantificação daquelas de múltipla escolha. De posse da transcrição das respostas para as perguntas discursivas, foi elaborada uma análise, semelhante à análise de conteúdo temática ${ }^{9,20}$. A análise de conteúdo pode ser aplicada a discursos e é baseada na dedução ou inferências sistemáticas, de forma objetiva, identificando algumas características da mensagem, por meio da construção de categorias, reunidas por temas de significação ${ }^{21}$.

Dessa forma, buscou-se o que havia de comum entre os relatos analisados que foram agrupados em grandes temas ${ }^{22,23}$, procurando-se fazer um recorte dos relatos transcritos de acordo com os conteúdos apresentados, categorizando as unidades de respostas que representavam o conjunto de idéias comuns ao grupo pesquisado. Após essa análise, foram designadas as seguintes categorias: 1) Início do processo de desenvolvimento da linguagem escrita; 2) Fatores que favorecem o processo de desenvolvimento da linguagem escrita; 3 ) Origem das dificuldades no processo de desenvolvimento da linguagem escrita; e 4) Condutas de educadores frente às dificuldades no processo de desenvolvimento da linguagem escrita. Sobre a apresentação dos resultados, estes foram dispostos em Figuras, contendo as frequências relativa e absoluta, de cada uma dessas categorias.

\section{Cuidados éticos}

Esta pesquisa só foi iniciada após receber as assinaturas dos Termos de Consentimento Livre e Esclarecidos (TCLE) de cada um dos professores 
voluntários. Desse modo, o estudo respeitou todas as normas estabelecidas pela resolução 196/96, acerca dos aspectos éticos em pesquisas com seres humanos e está aprovada pelo Comitê de Ética da Universidade Estadual do CentroOeste (UNICENTRO), sob o protocolo de número $10181 / 2008$.

\section{Análise estatística}

Os dados obtidos foram analisados de modo descritivo, apresentando-se as frequências absolutas (números absolutos) e relativas (percentuais).

\section{RESULTADOS E DISCUSSÃO}

Os resultados serão apresentados por meio de Figuras e Tabelas, seguidos de descrição e discussão acerca do conteúdo dos mesmos. Na Figura 1 será exposto o perfil dos educadores e nas tabelas, as categorias temáticas que foram elaboradas, a partir das respostas dos participantes.

\section{Perfil dos educadores}

Conforme pode ser observado na Figura 1, a seguir, todos os professores são do sexo feminino e a faixa etária dos mesmos variou de 27 a 50 anos de idade, com média de 34,7. O tempo de atuação variou bastante, indo de dois a trinta e dois anos. Sobre a escolaridade, há professores com formação em nível de médio, superior incompleto e superior completo. Esse dado merece destaque.

A formação dos professores é condizente com o que é preconizado pela LDB (1996), ou seja, todos tem no mínimo formação em nível médio, que é o critério mínimo exigido para se trabalhar com alfabetização no $1^{\circ}$ segmento do Ensino Fundamental. Sabe-se que o perfil ideal para essa atuação é o de um professor graduado, entretanto, na prática, o que se vislumbra, são muitos profissionais apenas com formação em nível médio (Magistério).

\begin{tabular}{|c|c|c|c|c|}
\hline Professores & Idade & Sexo & Formação & Tempo de atuação \\
\hline P1 & 30 & $\mathrm{~F}$ & Ensino Superior completo & 7 anos \\
\hline $\mathrm{P} 2$ & 34 & $\mathrm{~F}$ & Ensino Superior completo & 12 anos \\
\hline P3 & 27 & $\mathrm{~F}$ & Ensino Superior completo & 7 anos \\
\hline P4 & 33 & $\mathrm{~F}$ & Ensino Superior completo & 11 anos \\
\hline P5 & 32 & $\mathrm{~F}$ & Ensino Superior completo & 11 anos \\
\hline P6 & 37 & $\mathrm{~F}$ & Ensino Superior completo & 18 anos \\
\hline P7 & 36 & $\mathrm{~F}$ & Ensino Superior completo & 10 anos \\
\hline P8 & 45 & $\mathrm{~F}$ & Ensino Médio completo & 24 anos \\
\hline P9 & 50 & $\mathrm{~F}$ & Ensino Superior completo & 32 anos \\
\hline P10 & 32 & $\mathrm{~F}$ & Ensino Superior completo & 12 anos \\
\hline P11 & 41 & $\mathrm{~F}$ & $\begin{array}{l}\text { Ensino Superior } \\
\text { incompleto }\end{array}$ & 14 anos \\
\hline $\mathrm{P} 12$ & 39 & $\mathrm{~F}$ & Ensino Superior completo & 12 anos \\
\hline $\mathrm{P} 13$ & 31 & $\mathrm{~F}$ & Ensino Médio completo & 4 anos \\
\hline P14 & 28 & $\mathrm{~F}$ & $\begin{array}{l}\text { Ensino Superior } \\
\text { incompleto }\end{array}$ & 3 anos \\
\hline P15 & 31 & $F$ & $\begin{array}{l}\text { Ensino Superior } \\
\text { incompleto }\end{array}$ & 6 anos \\
\hline P16 & 38 & $\mathrm{~F}$ & Ensino Superior completo & 8 anos \\
\hline P17 & 36 & $\mathrm{~F}$ & Ensino Superior completo & 9 anos \\
\hline P18 & 26 & $\mathrm{~F}$ & Ensino Médio completo & 2 anos \\
\hline P19 & 34 & $\mathrm{~F}$ & $\begin{array}{l}\text { Ensino Superior } \\
\text { incompleto }\end{array}$ & 4 anos \\
\hline
\end{tabular}

Figura 1 - Caracterização dos participantes 
As diretrizes nacionais propõem uma formação do profissional obrigatoriamente em nível superior, como parte das propostas de melhoria do Ensino Fundamental, entretanto, essa proposta ainda está em viabilização e, por enquanto, não corresponde à realidade. Concomitante a isso, o Ministério da Educação, mais especificamente a Secretaria de Educação Básica elaborou diversos programas ao longo dos últimos anos. Estas ações, especialmente aquelas voltadas para a formação continuada, tem por objetivo dar maior suporte ao alfabetizador. Um exemplo foi a criação do Programa de Formação de Professores Alfabetizadores (PROFA) em 2001. Descrevendo de maneira simples, este programa tinha como objetivo qualificar educadores a respeito de temas ligados à alfabetização para que fossem capazes de transmitir esses conteúdos aos colegas, por meio de troca de experiências.

Imbernón ${ }^{24}$ comenta que o progresso da formação profissional é imprescindível para o avanço do quadro geral da educação, ou seja, as possibilidades de formação devem ser esgotadas, quando se trata de alfabetizar. É comum encontrar na fala dos próprios professores relatos de que no magistério Ihes faltam subsídios para alfabetizar. $\mathrm{O}$ autor comenta também que a formação adequada só será efetivada com a prática docente, ou seja, a eficácia em alfabetizar pode ser resultado da experiência do educador.

\section{O início do processo de desenvolvimento da linguagem escrita}

As concepções a respeito do início do processo de desenvolvimento da linguagem escrita podem variar de acordo com os mais diversos aspectos envolvidos na prática profissional, mas, sem dúvida, as bases teóricas que os profissionais tiveram contato em sua formação refletem nessas ações do dia-a-dia e, consequentemente, nessas concepções.

Tabela 1 - Relatos sobre o início do processo de construção da linguagem escrita

\begin{tabular}{lcc}
\hline Categorias temáticas & Frequência absoluta $\left(\mathbf{n}^{\mathbf{1}}\right)$ & Frequência relativa $(\%)$ \\
\hline Fase escolar & 7,0 & 35,0 \\
Fase pré-escolar & 6,0 & 30,0 \\
Primeiros desenhos em papel & 4,0 & 20,0 \\
Desde o nascimento & 2,0 & 10,0 \\
Ato motor da escrita & 1,0 & 5,0 \\
\hline Total & 20,0 & 100,0 \\
\hline
\end{tabular}

1 - Os dados da frequência absoluta expressam a possibilidade de mais de uma resposta por participante.

Quando questionados a este respeito, foram obtidos sete $(35 \%)$ relatos de que este processo se inicia a partir da entrada da criança na escola, ou seja, quando é formalizado o aprendizado da linguagem escrita. Seis relatos $(30 \%)$ indicaram a fase que antecede o ensino formal, na creche, por exemplo, como o marco inicial desse processo. Também houve menções $(20 \%)$ dos registros em papel como sendo o início do processo de desenvolvimento da linguagem escrita. Por outro lado, poucos $(10 \%)$ relatos indicaram o início do desenvolvimento da linguagem escrita, desde o nascimento da criança, ou seja, a partir das suas experiências ou contatos com essa modalidade de linguagem. E, por fim, foi obtida uma $(5,0 \%)$ resposta que mencionou 0 ato de segurar o lápis e rabiscar no papel como sendo o início da escrita.

Investigar este aspecto é de extrema importância para o trabalho fonoaudiológico em âmbito educacional, haja vista, que estas opiniões refletem uma maneira de atuar do educador que, por sua vez, direcionará as discussões e práticas do fonoaudiólgo nesse ambiente.

Para Cagliari25 a opinião do professor acerca do processo de construção da linguagem escrita é de suma importância já que o mesmo deve enxergar o sujeito que está em processo de aquisição. Quando o sujeito aprendiz chega à escola ele não está ausente às questões de leitura e escrita, ao contrário, já foi capaz de tecer representações a respeito desse processo, muito embora ainda tenham um longo caminho pela frente

Para Brito ${ }^{26}$ os fatores citados são parte de um processo que, acima de tudo, é linguístico, ou seja, a construção da linguagem escrita envolve aspectos individuais e sociais. A autora comenta também que a escrita não se trata apenas de um instrumento que a criança utilizará durante seu processo de 
aprendizagem, mas sim de um "produto cultural". A partir dessa afirmação pode-se imaginar o quão antes da entrada na escola se inicia o processo de construção da escrita no sentido de que a criança é um produto de sua cultura, desde que nasce.

Desse modo, não se pode deixar de considerar que o processo de desenvolvimento da linguagem escrita acontece por duas vias: uma que envolve a construção das relações fonema/ grafema de codificação e decodificação, articulada aos aspectos neuropsicomotores e uma segunda via que trata aspectos mais amplos relacionados ao desenvolvimento, ou seja, que trata das práticas sociais e do uso da linguagem escrita ${ }^{2,27-29}$.

\section{Fatores que favorecem o processo de desenvolvimento da linguagem escrita}

Muitos são os fatores que interferem no processo de desenvolvimento da linguagem escrita podendo estes estarem relacionados a aspectos individuais e sociais ou ambientais. A não compreensão disso pode levar os profissionais e os cuidadores a pensarem que os insucessos escolares estão diretamente relacionados somente à criança.

Tabela 2 - Fatores que podem favorecer o processo de construção da linguagem escrita

\begin{tabular}{lcc}
\hline Categorias temáticas & Frequência absoluta $\left.\mathbf{( n}^{\mathbf{2}}\right)$ & Frequência relativa (\%) \\
\hline Contato com materiais escritos & 12,0 & 30,0 \\
Interação/contexto familiar & 11,0 & 27,5 \\
Brincadeiras & 9,0 & 22,5 \\
Consciência fonológica & 4,0 & 10,0 \\
Interesse & 2,0 & 5,0 \\
Contato com arte (música, literatura) & 1,0 & 2,5 \\
Compreender a importância de ler e & 1,0 & 2,5 \\
escrever & 40,0 & 100,0 \\
\hline Total &
\end{tabular}

2 - Os dados da frequência absoluta expressam a possibilidade de mais de uma resposta por participante.

Observa-se, na Tabela 2, que foram citados aspectos variados em relação às possibilidades de favorecer o processo de desenvolvimento da linguagem escrita. Nas categorias mencionadas, é possível verificar que os educadores tendem a indicar mais os fatores individuais e familiares em detrimento dos escolares. Isso não é coerente com o que foi verificado anteriormente, pois a maior parte dos educadores relatou que processo de desenvolvimento da linguagem escrita começa na escola. Para que eles fossem coerentes, nesse momento, eles deveriam relatar aspectos escolares como os maiores favorecedores desse processo.

Caso essa responsabilidade seja delegada para profissionais externos à escola ou familiares, a tendência ao encaminhamento das crianças com dificuldades será grande. Mesmo que sejam simples, ou dificuldades relacionadas ao processo de adaptação escolar, estas serão concebidas como alterações e, por isso os educadores sentem a necessidade de realizar o encaminhamento, prática bastante comum.

Nesse sentido, a fonoaudiologia tem muito a contribuir, em relação ao trabalho em âmbito escolar, indicando aos professores de que forma estas dificuldades podem ser resolvidas, sem encaminhar essas crianças. A assessoria fonoaudiológica tem esse intuito, ou seja, de discutir, e construir propostas junto ao educador. Propostas estas que possam ser aplicadas em sala de aula pelo próprio educador, pois elas se traduzem, por exemplo, em adaptações de atividades pedagógicas ${ }^{10}$.

Os trabalhos com o intuito de ampliar a atuação da Fonoaudiologia Escolar estão cada vez mais expressivos, sejam estes com foco para a formação continuada $^{10}$ seja para intervenções educacionais em ambiente escolar ${ }^{30}$.

Por outro lado, ainda há muitos trabalhos exclusivamente de cunho preventivo, cujo objetivo é o de apenas detectar alterações fonoaudiológicas e encaminhá-las aos atendimentos clínicos. Por isso, deve-se tomar o devido cuidado em relação às orientações aos professores, pois como alerta Barcellos $^{31}$ (p. 25) "a orientação (...) traz em si a crença de que os distúrbios da linguagem podem ser evitados por meio de ações pedagógicas. Estas ações correspondem à orientação aos professores quanto à estimulação auditiva e visual para a produção adequada dos sons da fala". Esse proce- 
dimento não é coerente com as propostas atuais de assessoria fonoaudiológica e, devem, na medida do possível, serem minimizados.

Essa assessoria deve ter um foco diferenciado de atuação, no sentido de propor atividades que sejam integradas às dos educadores, criando condições para que a escola e a família participem efetivamente do processo de escolarização dentro e fora do ambiente escolar. Dessa maneira, o fonoaudiólogo poderá propor ações dentro da escola que não priorizem as alterações no desenvolvimento dos escolares, mas sim criando condições para o aprimoramento da comunicação oral e escrita e consequentemente um desempenho escolar satisfatório, tendo como base fundamental o trabalho do educador dentro da sala de aula ${ }^{10,13}$.

\section{A origem das dificuldades no processo de desenvolvimento da linguagem escrita}

Entre os profissionais que trabalham com alfabetização é comum de se encontrar opiniões distintas a respeito do processo de desenvolvimento da linguagem escrita. Da mesma maneira, as opiniões diferem no que se refere às causas das dificuldades escolares. Essas opiniões refletem no trabalho desenvolvido em sala de aula. Identificar e refletir sobre as causas e origens deste problema pode colaborar para suas soluções.

Tabela 3 - Relatos sobre a origem das dificuldades no processo de construção da linguagem escrita

\begin{tabular}{lcc}
\hline Categorias temáticas & Frequência absoluta $\left(\mathbf{n}^{3}\right)$ & Frequência relativa $(\%)$ \\
\hline Fatores intrínsecos à criança/ & 16,0 & 38,0 \\
patologias/saúde & 9,0 & 21,5 \\
Falta de estímulo & 7,0 & 16,5 \\
Interação familiar de baixa qualidade & 6,0 & 15,0 \\
Problemas em linguagem oral & 2,0 & 5,0 \\
Metodologias de ensino e aprendizagem & 1,0 & 2,0 \\
inadequadas & & \\
Multifatorial & 1,0 & 2,0 \\
Diferenças culturais & 42,0 & 100,0 \\
Não respondeu & Total & .
\end{tabular}

3 - Os dados da frequência absoluta expressam a possibilidade de mais de uma resposta por participante.

Observa-se, na Tabela 3, que é bastante expressiva a quantidade de vezes que os participantes citam fatores inerentes à criança como causa do insucesso no processo de desenvolvimento da linguagem escrita. Este insucesso estaria relacionado aos fatores de ordem neurológica, fisiológica e psicológica. De maneira geral, a maioria das categorias expressa situações em que o fracasso do aluno não teria relação com a metodologia de ensino. Isso evidencia, por sua vez, que os educadores pouco $(5,0 \%)$ admitiram a possibilidade da interferência da metodologia de trabalho na aprendizagem dos alunos.

Outro fator bastante citado foi a falta de estímulo $(21,5 \%)$. Neste ponto pode-se questionar a quais estímulos os participantes se referem, já que anteriormente a maioria citou a entrada na escola como sendo o momento em que a linguagem escrita começa a se desenvolver. Na escola o professor é o responsável por este processo. Sendo assim, a falta de estímulo poderia estar relacionada às outras questões, também escolares. Novamente reafirma-se que o desenvolvimento da linguagem escrita está ligado a diversos fatores, especialmente aos sociais $2,27,28,31$.

$\mathrm{Na}$ literatura é comum serem encontrados rabalhos comentando a respeito do papel cultural da linguagem escrita ${ }^{32,33,29}$ e também da reduzida importância que tem se dado a esta modalidade de linguagem ao longo dos anos ${ }^{26,25,34}$. Estes aspectos se refletem nas respostas dos participantes que não citam a cultura ou a própria prática pedagógica como fatores interferentes.

\section{Condutas de educadores frente às dificuldades no processo de desenvolvimento da linguagem escrita}

Infelizmente é comum que o educador se depare com casos de insucesso no processo ensinoaprendizagem. Este profissional pode ter diversas atitudes buscando ajudar o aluno em questão. Tem-se observado que o recurso mais utilizado 
pelos educadores é o encaminhamento à equipe pedagógica e a outros profissionais como o psicopedagogo, o psicólogo e o fonoaudiólogo. Na atuação, dentro da escola, um dos papéis fundamentais do fonoaudiólogo é apresentar ao professor alternativas para ajudar o aluno com dificuldades.

\section{Tabela 4 - Relatos sobre condutas diante das dificuldades no processo de construção da linguagem escrita}

\begin{tabular}{lcc}
\hline Categorias temáticas & Frequência absoluta $\left(\mathbf{n}^{4}\right)$ & Frequência relativa $(\%)$ \\
\hline Encaminhamentos para outros & 12,0 & 39,0 \\
profissionais & 4,0 & 13,0 \\
Encaminhar para o contraturno & 4,0 & 13,0 \\
Separar os alunos & 4,0 & 13,0 \\
Conhecer mais sobre a dificuldade & 3,0 & 9,5 \\
Pedir apoio familiar e orientar & 3,0 & 9,5 \\
Atividades alternativas & 1,0 & 3,0 \\
Mudanças em relação à metodologia de & & \\
ensino e aprendizagem & 31,0 & 100,0 \\
Contextualizar as atividades & & \\
\hline Total &
\end{tabular}

4 - Os dados da frequência absoluta expressam a possibilidade de mais de uma resposta por participante.

Pode-se observar, na Tabela 4, que algumas das soluções comentadas pelas professoras podem refletir o conhecimento e a percepção delas a respeito das dificuldades escolares. Os encaminhamentos a outros profissionais, citados 12 vezes, podem refletir uma insegurança ou a falta de recursos de se trabalhar com esses alunos em sala de aula. Soluções como encaminhar para contraturno e separar os alunos mostram que os participantes tem uma percepção que indica uma homogeneidade a respeito dos aprendizes ${ }^{35}$. Além disso, indica um perfil de um profissional que se ausenta dessas questões.

Por outro lado, respostas positivas também foram citadas (atividades alternativas, mudanças na metodologia, buscar conhecer as dificuldades de aprendizagem). Tais relatos expressam que o educador reconhece seu papel e mostra disponibilidade em enfrentar essas questões. E estes relatos vão ao encontro daqueles achados na pesquisa de Freschi ${ }^{36}$, na qual o autor observou que os professores indicaram que é necessário diversificar os procedimentos metodológicos usados em sala de aula.

Ainda, pode-se analisar as respostas da Tabela 4, relacionando-as com aquelas apresentadas na Tabela 3 , ou seja, já que o fator causal da dificuldade no processo de desenvolvimento da linguagem escrita é inerente à criança, é natural que as condutas não estejam relacionadas à ações pedagógicas. Nesse sentido, sabe-se que não se deve centrar apenas em uma instância a responsabilidade por dificuldades relacionadas a um contexto abrangente e que envolve múltiplas variáveis. Ademais, não se pode retirar da escola a sua principal responsabilidade que é a de alfabetizar ${ }^{29}$.

\section{CONCLUSÕES}

Os dados obtidos ao longo dessa investigação permitiram concluir que, embora a maioria dos professores tenha formação condizente com o que é preconizado pela LDB, estes possuem carência de conhecimentos fundamentais para a sua prática no que concerne o processo de alfabetização. Isso é refletido em conhecimentos insuficientes em relação às questões essenciais do processo de desenvolvimento da linguagem escrita, como: quando se inicia esse processo, fatores que o favorecem, origem de suas dificuldades e condutas diante destas.

Diante desses dados, é possível inferir também que os trabalhos de formação continuada desenvolvidos pela Fonoaudiologia Escolar devem permanecer como prioridade dessa área, pois são os que mais propiciam trocas de conhecimentos no ambiente escolar. A assessoria fonoaudiológica escolar pode contribuir de maneira importante nestes casos e, sem dúvida, é o caminho para que o foco do trabalho do fonoaudiólogo neste ambiente esteja mais voltado para a promoção do desenvolvimento infantil de da saúde.

Reafirma-se, portanto, que o fonoaudiólogo assessor deve atuar de modo conjunto, refletindo sobre os saberes e dizeres dos professores, com o intuito de construir práticas articuladas com a proposta pedagógica escolar. 


\section{ABSTRACT}

Purpose: to describe a proposal that may contribute to the development of actions promoting health to back Speech therapists performance in school, based on educators' investigation on conceptions about the written language development process. Method: descriptive study performed through application of questionnaires in nineteen elementary school teachers in three public schools in a city in the State of Parana. The questionnaires contained questions on the development of written language, factors that favor and/or hinder this process. Data analysis was carried out through transcription of discursive replies and quantification of multiple-choice answers. From the content submitted in the replies, it was possible to create subject areas to be discussed. Results: seven reports (35\%) showing that the development process of written language starts at school were recorded; contact with writing was quoted twelve times (30\%) as support for the development of written language; individual aspects were reported sixteen times (38\%) as causes for learning difficulties; and there were twelve reports (39\%) on forwarding to other professionals as a solution for such difficulties. Conclusion: educators have lack of fundamental knowledge for their educational practice regarding the literacy process, although most have training being consistent with what is advocated by LDB. It is not possible to generalize this conclusion, due to the small sized study sample.

KEYWORDS: Speech, Language and Hearing Sciences; Health Promotion; Faculty; Child Language

\section{REFERÊNCIAS}

1. Oliveira JP, Braga TMS. Desenvolvimento Infantil: perspectivas de atuação em educação e saúde. 1. Ed. Marília: Fundepe Editora; 2009.

2. Barros TN, Gomes, E. O perfil dos professores leitores das séries iniciais e a prática de leitura em sala de aula. Rev. CEFAC [periódico na Internet]. 2008 [acesso em 08 de dezembro de 2010]; 10(3): 332-42. Disponível em: www.scielo.br/revistas/ rcefac.

3. Pilz EML, Schermann LB. Determinantes biológicos e ambientais no desenvolvimento neuropsicomotor em uma amostra de crianças de Canoas/RS. Ciência \& Saúde Coletiva. 2007; 12(1):181-90.

4. Grantham-Mcgregor S, Cheung YB, Cueto S, Glewwe P, Richter L, Strupp B. Developmental potential in the first 5 years for children in developing countries. Lancet. 2007; 369 (9555): 60-70.

5. Silverstein M, Sand N, Glascoe FP, Gupta VB, Tonniges TP, O'Connor KG. Pediatrician practices regarding referral to early intervention services: is an established diagnosis important? Ambul Pediatr. 2006; 6:105-9.

6. Beggs S, Sewell J, Efron D, Orkin C. Developmental assessment of children: a survey of Australian and New Zealand paediatricians. J Paediatr Child Health. 2005; 41(8):444-8.

7. CFFa. Conselho Federal de Fonoaudiologia. Resolução $n^{\circ}$ 309, de $1^{\circ}$ de abril de 2005. Disponível em: www.fonoaudiologia.org.br, acessada em 10 de dezembro de 2009.
8. Sícoli JL, Nascimento PR. Promoção de saúde: concepções, princípios e operacionalização. Interface - Comunicação, Saúde, Educação. 2003; 7(12):101-22.

9. Hekavei T, Oliveira JP. Evoluções motoras e linguísticas de bebês com atraso de desenvolvimento na perspectiva de mães. Rev. bras. educ. espec. [periódico na Internet]. 2008 [acesso em 08 de dezembro de 2010]. 2009 [acesso em 02 de fevereiro de 2011], 15(1): 31-44. Disponível em: www.scielo.br.

10. Oliveira RT, Zaboroski AP, Oliveira JP, Bougo GC. Assessoria Fonoaudiológica na Educação Infantil. Rev Conexão UEPG. 2010; 1(6):78-83.

11. Zaboroski AP, Oliveira JP. Algumas considerações sobre o favorecimento do processo de desenvolvimento e aprendizagem. In: Oliveira JP, Braga TMS. (Eds.). Desenvolvimento Infantil: perspectivas de atuação em educação e saúde. 1. ed. Marília: Fundepe Editora. 2009. 128-41.

12. Calheta PP. Fonoaudiologia e Educação: sentidos do trabalho de assessoria a escolas públicas. In: Cesas CPAHR, Calheta PP. (Orgs.). Assessoria e Fonoaudiologia: perspectivas de ação. 1. ed. Rio de Janeiro: Revinter; 2005. 103-15. 13. Luzardo R., Nerm K. Instrumentalização fonoaudiológica para professores da educação infantil. Rev CEFAC. 2006; 8(3):289-300.

14. Fernandes GB, Crenitte PAP. O conhecimento de professores de $1^{\underline{a}}$ a $4^{a}$ série quanto aos distúrbios da leitura e escrita. Rev. CEFAC. 2008;8(2):182-90. 15. Campos CEA. O desafio da integralidade segundo as perspectivas da vigilância 
da saúde e da saúde da família. Ciênc Saúde Coletiva. 2003; 8(2): 569-84.

16. Campos CEA. A organização dos serviços de atenção primária à saúde no Brasil. Revista Brasileira de Medicina de Família e Comunidade. 2006; 2(6).131-47.

17. Ramos AS, Alves LM. A fonoaudiologia na relação entre escolas regulares de ensino fundamental e escolas de educação especial no processo de inclusão. Rev. bras. educ. espec. [periódico na Internet]. 2008 [acesso em 08 de dezembro de 2010]; 14(2):235-50. Disponível em: www.scielo.br.

18. Gonçalves FD, Catrib AMF, Vieira NFC, Vieira LJES. A promoção da saúde na educação infantil. Interface - Comunicação, Saúde, Educação. 2008; 12(24):181-92.

19. Gil AC. Métodos e técnicas de pesquisa social. 5 ed. São Paulo: Atlas. 2006.

20. Bardin L. Análise de conteúdo. Lisboa, Edições 70, 1977.

21. Bauer WM. Análise de conteúdo clássica: uma revisão. In: Bauer MW, Gaskell G. (Eds.). Pesquisa qualitativa com texto, imagem e som: um manual prático. Trad.: Pedrinho A. Guareschi. 1. ed. Petrópolis: Vozes. 2000. 189-217.

21. Myers G. Análise da conversação e da fala. In: Bauer MW, Gaskell G. (Eds.). Pesquisa qualitativa com texto, imagem e som: um manual prático. Trad.: Pedrinho A. Guareschi. 1. ed. Petrópolis: Vozes. 2000. 271-92.

23. Monteiro APH, Manzini EJ. Mudanças nas concepções do professor do ensino fundamental em relação à inclusão após a entrada de alunos com deficiência em sua classe. Rev. bras. educ. espec. [periódico na Internet]. 2008 [acesso em 08 de dezembro de 2010], 14(1): 35-52. Disponível em: www.scielo.br.

24. Imbernón F. Formação Docente e Profissional: formar-se para a mudança e a incerteza. 5 ed. São Paulo: Cortez; 2005.

http://dx.doi.org/10.1590/S1516-18462011005000076

RECEBIDO EM: 03/03/2011

ACEITO EM: 21/4/2011

Endereço para correspondência:

Jáima Pinheiro de Oliveira

Universidade Estadual do Centro-Oeste

(UNICENTRO)

Setor de Ciências da Saúde - SES/I

Departamento de Fonoaudiologia

PR 153 - km 07 - Riozinho - Caixa Postal 21

Irati - PR

CEP: 84.500 .000

E-mail: jaimafono@gmail.com
25. Cagliari LC. Alfabetizando sem o bá . bé . bi . bó . bu. 1. ed. São Paulo: Scipione; 1999.

26. Brito $A E$. Prática pedagógica alfabetizadora: a aquisição da língua escrita como processo sociocultural. Revista Iberoamericana de Educación. 2007; 44(4):12-20.

27. Fontes MJO, Cardoso-Martins C. Efeitos da leitura de histórias no desenvolvimento da linguagem de crianças de nível sócio-econômico baixo. Rev Psic Reflex Crít. 2004;17(1):83-94.

28. Gomes MLM. Da materialidade do texto à constituição do leitor: a prática interacionista da leitura como ponto de partida para a instigação sócio-cognitiva. Rev Vértices. 2003; 5(3):81-8.

29. Machado MLCA, Berberian AP, Santana AP. Linguagem escrita e subjetividade: implicações do trabalho grupal. Rev. CEFAC [periódico na Internet]. 2009 [acessado em 08 de fevereiro de 2011]; 11(4): 713-9. Disponível em: www.scielo.br. 30. Romano-Soares S, Soares AJC, Cárnio MS. Práticas de narrativas escritas em estudantes do ensino fundamental. Pró-Fono R. Atual. Cient. [periódico na Internet]. 2010 [acesso em 08 de fevereiro de 2011]; 22(4): 379-84. Disponível em: www.scielo.br.

31. Barcellos CAP. Assessoria Escolar em Fonoaudiologia: sob o efeito da escrita e sua aquisição [Dissertação de Mestrado em Fonoaudiologia]. São Paulo: PUC; 2003.

32. Tuleski SC, Eidt NM. Repensando os distúrbios de aprendizagem a partir da psicologia históricocultural. Psicol. Estud. 2007; 12(3):531-40.

33. Gontijo CMM, Leite SA. A escrita como recurso mnemônico na fase inicial de alfabetização escolar: Uma análise histórico-cultural. Educ Social. 2002; 23(78):143-67.

34. Santos WLP. Educação científica na perspectiva de letramento como prática social: funções, princípios e desafios. Rev. Bras. Educ. [periódico na Internet]. 2007 [acesso em 08 de dezembro de 2010]; 12 (36): 474-92. Disponível em: www.scielo.br.

35. Cruz MRDF. Desmistificando o mito da turma homogênea: caminhos duma sala de aula inclusiva. Rev. Ed. Esp. 2010. [periódico na Internet]. 2010 [acesso em 08 de dezembro de 2010]; 23 (36): 27-42. Disponível em: www.ufsm.br/ revistaeducacaoespecial.

36. Freschi M. As percepções docentes sobre a dimensão metodológica no processo ensinoaprendizagem. Práxis Educativa. 2008. [periódico na Internet]. 2008. [acesso em 08 de dezembro de 2010]; 3(2): 149-57. Disponível em: http://dx.doi. org/10.5212/PraxEduc.v.3i.2.149157. 